\title{
Purely Laparoscopic Left Hepatectomy with Intracorporeal Choledochojejunostomy for Recurrent Pyogenic Cholangitis
}

\section{Kil Hwan Kim, MD}

Department of Surgery, Dankook University Hosptial, Cheonan, Korea.

\section{YoungRok Choi, MD}

Department of Surgery, Seoul National University College of Medicine, Seoul National University Bundang Hospital, Seongnam, Korea.

E-mail: choiyoungrok@gmail.com

\section{Ho-Seong Han, MD, PhD}

Department of Surgery, Seoul National University College of Medicine, Seoul National University Bundang Hospital, Seongnam, Korea.

Yoo-Seok Yoon, MD, PhD

Department of Surgery, Seoul National University College of Medicine, Seoul National University Bundang Hospital, Seongnam, Korea.

\section{Jai Young Cho, MD, PhD}

Department of Surgery, Seoul National University College of Medicine, Seoul National University Bundang Hospital, Seongnam, Korea.

This video was presented at the podium in SAGES 2018.

(c) Mary Ann Liebert, Inc. DOI: 10.1089/vor.2019.0599
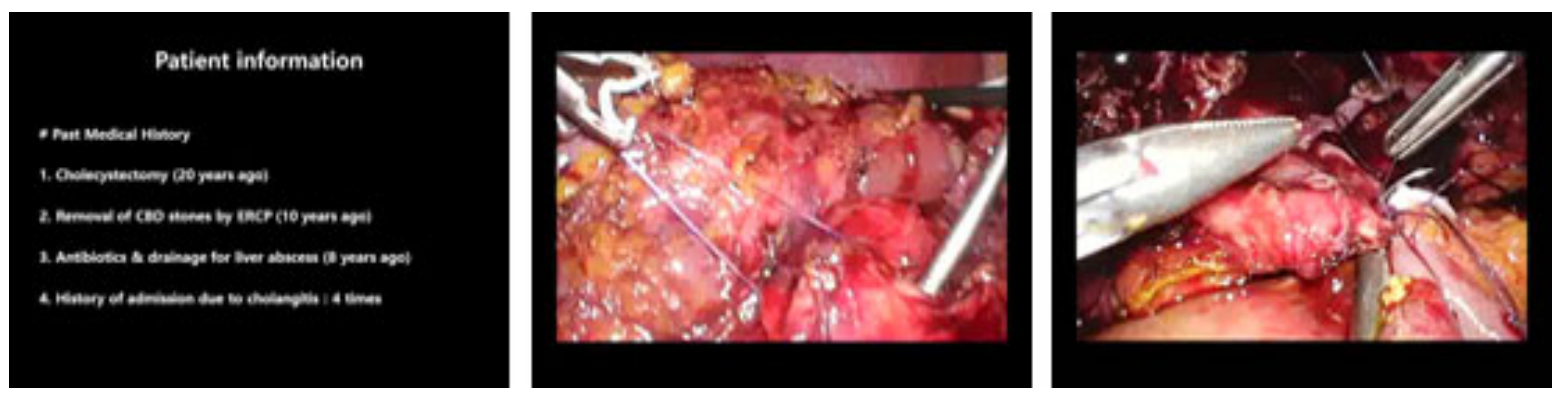

\section{Abstract}

Introduction: Laparoscopic liver resection is currently done for benign lesions of the biliary tract, ${ }^{1,2}$ with some biliary diseases requiring bypass surgery as well as liver resection. ${ }^{3}$ Many centers have been trying to reduce the extent of operative wounds using various methods. ${ }^{4-6}$ Although there are no clear criteria of hepatic resection for intrahepatic duct stones, most of the surgeons are performing hepatectomy in these cases: (1) hepatolithiasis is localized in the unilateral lobe, (2) the intrahepatic bile duct containing stones is markedly constricted or dilated, (3) hepatolithiasis is accompanied by hepatic lesions including hepatic abscess or atrophy, and (4) combination with intrahepatic cholangiocarcinoma. ${ }^{7}$ In this video, we introduce the purely laparoscopic left hemihepatectomy with choledochojejunostomy and specimen extraction through the vagina.

Materials and Methods: A 66 year-old woman who underwent cholecystectomy and medical treatment for the liver abscess visited the hospital complaining of epigastric pain and radiating pain to left shoulder. A preoperative CT shows left intrahepatic duct stone with atrophied left liver. The patient 
was placed in lithotomy position, with the main operator on the patient's right side. We used a $10 \mathrm{~mm}$ laparoscopic flexible endoscope and five trocars. There were moderate adhesions in the peritoneal cavity caused by previous cholecystectomy and recurrent cholangitis. Because the left portal vein was obliterated attributable to thrombosis, a prominently demarcated ischemic line was identified after ligation of the left hepatic artery. During hepatic dissection, the middle hepatic vein was exposed and preserved. The left Glissonean pedicle was ligated and transected using the Endo-stapler. Three openings were identified: the right bile duct, left bile duct, and the caudate bile duct. Intracorporeal choledochojejunostomy was then done using a continuous suture. The liver specimen was placed inside an extraction bag and removed through the posterior fornix of the vagina and the vaginal canal by the gynecologist.

Results: The operation took 200 minutes and estimated blood loss was at $200 \mathrm{~mL}$. The drain was removed at postoperative 4 days and the patient was discharged the same day. Final histopathologic report showed hepatolithiasis with focal hepatic parenchymal atrophy without hidden malignancy such as intrahepatic cholangiocarcinoma.

Conclusions: This video shows the technical feasibility of purely laparoscopic left hemihepatectomy with intracorporeal choledochojejunostomy for recurrent intrahepatic pyogenic cholangitis. In addition, specimen extraction through the vaginal canal is a useful adjunct technique for minimally invasive surgery.

Acknowledgments: Authors thank Woo Chul Kim, MD, for the help in improving the use of English in the article and recording a narration.

No competing financial interests exist.

Runtime of video: 7 mins 54 secs

This video was presented at the podium in SAGES 2018.

Keywords: choledochojejunostomy, IHD stone, specimen extraction

\section{Cite this video}

Kil Hwan Kim, YoungRok Choi, Ho-Seong Han, Yoo-Seok Yoon, Jai Young Cho, Purely Laparoscopic Left Hepatectomy with Intracorporeal Choledochojejunostomy for Recurrent Pyogenic Cholangitis, Videoscopy. 2019, DOI: 10.1089/vor.2019.0599.

\section{References}

1. Yoon YS, Han HS, Shin SH, Cho JY, Min SK, Lee HK. Laparoscopic treatment for intrahepatic duct stones in the era of laparoscopy: Laparoscopic intrahepatic duct exploration and laparoscopic hepatectomy. Ann Surg 2009;249:286-291.

2. Vibert E, Perniceni T, Levard H, Denet C, Shahri NK, Gayet B. Laparoscopic liver resection. Br J Surg 2006;93:67-72.

3. Chowbey PK, Soni V, Sharma A, Khullar R, Baijal M. Laparoscopic hepaticojejunostomy for biliary strictures: The experience of 10 patients. Surg Endosc 2005;19:273-279.

4. Diao M, Li L, Li Q, Ye M, Cheng M. Single-incision versus conventional laparoscopic cyst excision and Roux-Y hepaticojejunostomy for children with choledochal cysts: A case-control study. World J Surg 2013;37:1707-1713.

5. Choi SB, Park JS, Kim JK, Hyung WJ, Kim KS, Yoon DS, et al. Early experiences of robotic-assisted laparoscopic liver resection. Yonsei Med J. 2008;49:632-638.

6. Nishimura A, Kawahara M, Suda K, Makino S, Kawachi Y, Nikkuni K. Totally laparoscopic sigmoid colectomy with transanal specimen extraction. Surg Endosc 2011;25:3459.

7. Tazuma S, Unno M, Igarashi Y, Inui K, Uchiyama K, Kai M, et al. Evidence-based clinical practice guidelines for cholelithiasis 2016. J Gastroenterol 2017;52:276-300. 